\title{
An Empirical Application of Goal Programming and AHP in Real Estate Assessment
}

\author{
Hossein Jamshidi \\ Professor of Operations Management, Management Marketing and Logistic Department \\ College of Business and Public Affairs, Alabama A\&M University \\ E-mail: Hossein.jamshidi@aamu.edu
}

Larry McDaniel

Professor of Management, Management Marketing and Logistic Department

College of Business and Public Affairs, Alabama A\&M University

E-mail: larry.mcdaniel@aamu.edu

\section{Dana Harris}

Professor of Marketing, Management Marketing and Logistic Department

College of Business and Public Affairs, Alabama A\&M University

E-mail: dana.harris@aamu.edu

Received: April 12, 2017

Accepted: April 28, 2017 Published: July 1, 2017

doi:10.5296/jmr.v9i3.11074

URL: https://doi.org/10.5296/jmr.v9i3.11074

\begin{abstract}
The Goal Programming (GP) is one of the many models which have been developed to deal with the multiple objectives decision-making problems. This model allows taking into account, simultaneously, many objectives while the decision-maker is seeking the best solution from among a set of feasible solutions. At first, the aim of this study is to compare the objectives of the decision maker based on the Analytical Hierarchy Process (AHP) and to rank the objectives according to the AHP process and once the objectives are set then apply the GP to the facility allocation in a real estate rental property. The objective of decision maker is not only to maximize profit rather the decision maker has multiple objective to achieve. The methodology presented in this study can help the decision maker to formulate
\end{abstract}




\section{Macrothink}

Journal of Management Research ISSN 1941-899X 2017, Vol. 9, No. 3

viable location strategies in the volatile and complex facility allocation environment. This is an empirical study applied to a local business developer utilizing multi objective decision analysis tools.

Keywords: Decision Making, Goal Programming, Linear Programming, AHP, Assessment 


\section{Introduction}

In recent years, increasing attention has been paid to the problem of analyzing and selecting facility locations in the real estate investment context. In most approaches to facility location, the aim has been to choose a space in which the profit is maximized. In many location-allocation problems, cost minimization or profit maximization may not be the most important factor to consider rather the decision maker may have other agendas to achieve before aiming in maximizing profit or minimizing cost. This process of utilizing multiple criteria goals has been thoroughly discussed (Geoffrion, 1978). Many researchers have suggested numerous considerations or factors as important criteria for the location-allocation problem. These factors include availability of transportation facilities, cost of transportation, availability of labor, cost of living, availability and nearness to raw materials, proximity to markets, size of markets, attainment of favorable competitive positions, anticipated growth of markets, income and population trends, cost and availability of industrial lands, closeness to other industries, cost and availability of utilities, government attitudes, tax structure, community related factors, environmental considerations, assessment of risk, and return on assets.Many methodologies have been utilized to solve the location-allocation problem. The more obvious methodology has been the fundamental transportation/assignment and linear programming formulation. Integer and mixed integer formulations have been applied by many researchers (Toregas et al, 1971; Meyers, 1973; Jucker et al, 1976; Kennington, 1976; Mairs et al, 1978; Patel, 1979). Baumol, 1958, solved the location problem for minimum total delivery cost with nonlinear programming. Gyu and John, (2000)applied a goal programming model for project selection and resource planning. Masoudet al (2001) developed a project selection model for health service institutions that incorporated research and development, investment planning, capital budgeting, etc. Fabiane et al (2003) applied goal programming to Brazilian forest problem. The goal programming model was used seeking to reach the goals of harvesting pine, harvesting araucaria, Eva-mate harvest, tourism, employees, etc. The application of goal programming in budgetary allocation of higher learning institute was examined (Ekezie et al. 2013). The result of study demonstrated that all the goals formulated were met, except one.

Extensive effort has been devoted to solving location problems employing a wide range of objective criteria and methodologies used in the analysis. Geoffrion(1978), for example, includes decomposition, mixed integer linear programming, simulation and heuristics that may be used in analyzing location problems. He noted that a suitable methodology for supporting managerial decision making for location problems should be computationally efficient and leading to optimal solution, and being capable of further testing. Other researchers further stress the importance of multiple criteria that are to be included in the analysis(Erlenkotter, 1975; Tuckman 1975). The combination of analytical hierarchy process (AHP) and goal programming (GP) has been used (Badri, 2001) for quality control systems. He identified five quality identifies and weighted them by AHP. In another study,(Badri, 1999) integrated AHP and GP to address the facility location-allocation problem. He formulated viable location strategies in the volatile and complex global decision environment. He used AHP to indicate a preference or priority for each location alternative and then he applied GP 
to different criteria. The Goal Programming model is applied for allocation time and cost in project management (Abdeelkarim, 2015). He applied the Goal Programming to a construction company with three objectives. In another study Mubiru, (2010)applied the Goal Programming for allocation of time and cost in a project management environment.

This study is an empirical study in which a landlord has a 19,800 square feet of strip mall location and would like to rent out this facility to tenants. The objective of the landlord is not only to maximize profit from the rental locations rather the landlord has multiple objectives to achieve. Their vision is the long term profit by obtaining a big anchor in the center of this facility and then renting out the rest of the facility to smaller tenants. Therefore the landlord is aiming to rent a big portion of the 19800 square feet location to an anchor which occupies at least 6,000 square feet of occupancy. Secondly, the landlord wants to lease the entire 19,800 square feet so that no partial or extra space would be left out, and finally to maximize the profit from rentals. The goal programming model with multiple objectives is used to achieve the objectives and the priorities are measured by Analytical Hierarchy Process (AHP).

According to Decision Support System Resources, the definition of the Analytical Hierarchy Process (AHP) is an approach to decision making that involves structuring multiple choice criteria into a hierarchy, assessing the relative importance of these criteria, comparing alternatives for each criterion, and determining an overall ranking of the alternatives. Saaty, (180), the founder of the AHP, claims that the AHP is "natural to our intuition and general thinking," which combines logic and intuition and takes advantage of our ability to rank choices. The AHP asks respondents to rank them by using pair-wise comparisons and assign a number, representing weights, to each pair comparison. The numbers will generate a matrix giving the decision maker an organizational tool to attack the larger problem.

Additionally, AHP helps capture both subjective and objective evaluation measures, providing a useful mechanism for checking the consistency of the evaluation measures (Parcom, 2007). When the decision cycle involves taking into account a variety of multiple criteria, AHP splits the overall problem to solve into many evaluations of lesser importance, while keeping at the same time their part in the global decision.

\section{Methodology}

The study offers two methodologies for the location selection decision. The AHP is presented first as a stand-alone methodology and then a combination of AHP and GP model is presented as an extension to consider additional criteria in decision making process. As mentioned earlier, there are 19,800 square feet space to be subdivided into rental units. The units must be in combination of $1500,1800,2100,2400,3000,3600,6000$ or 9000 square feet with the total 19,800 square feet. In order to attract an anchor to the center, the decision maker is giving discounts per square feet for different sizes of tenant occupancy. The following Table represents the price per square feet and the monthly rental generated for each tenant unit size. The landlord wants to have an anchor, in the center of the center, to attract traffic and visibility. The size of each unit is predetermined so he does not want to deviate from the list in Table 1.The landlord wants a combination of the rental units, with inclusion of an anchor 
in the center, to fit total square feet available to maximize his return on property. The "maximum units" in the table represents the maximum possible units possible to have in the center.

Table 1. Income Generated From Different Size Unit

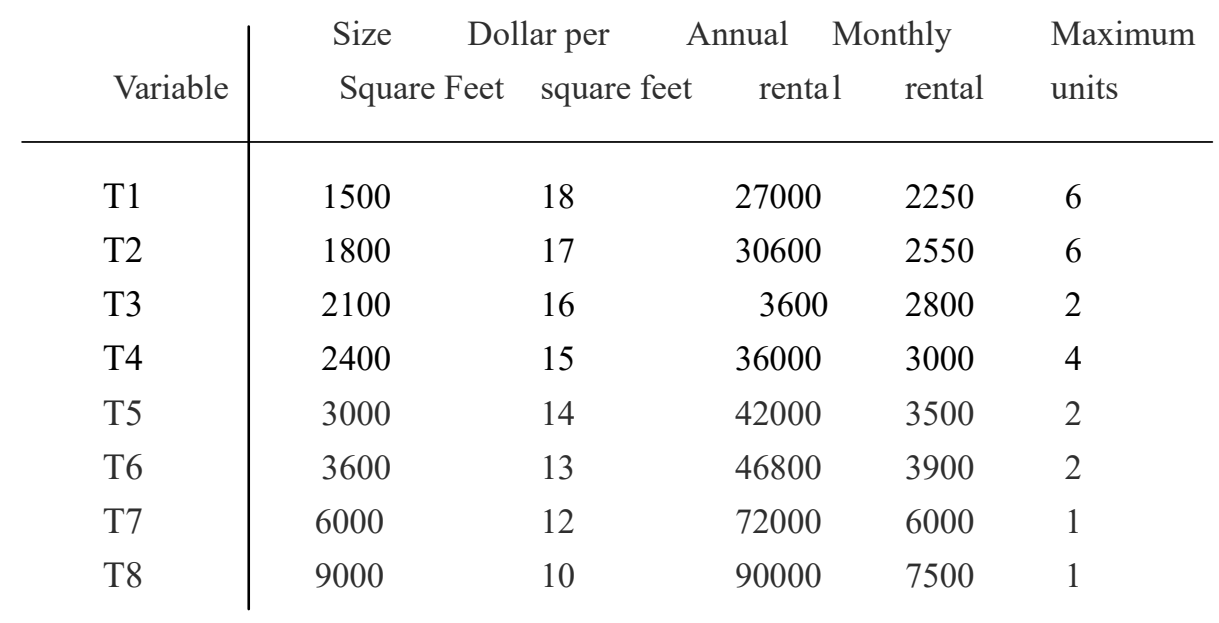

\section{Results}

The AHP process is used to prioritize the goals. AHP helps capture both subjective and objective evaluation measures, providing a useful mechanism for checking the consistency of the evaluation measures and alternatives suggested by the decision maker. Table 2 is designed to elicit and assess information on preferences for these rental units. The three objectives are compared based on paired wise comparisons. The landlord has assigned a weight of 5 to 1 , comparing anchor to occupancy, meaning having an anchor is 5 times as important as occupancy. Likewise occupancy is $1 / 5$ of anchor. Also anchor is 7 times as important as profit. Table 3 is developed based on percentages preferences of the landlord.

Table 2. Priority Assignment of the Objectives

\begin{tabular}{l|lll} 
& Anchor & Occupancy & Profit \\
\hline Anchor & 1 & 5 & 7 \\
Occupancy & $1 / 5$ & 1 & 3 \\
Profit & $1 / 7$ & $1 / 3$ & 1 \\
\hline Total & 1.34 & 6.33 & 10
\end{tabular}


Table 3. Percentage of Priority

\begin{tabular}{l|lll|l} 
& Anchor & Occupancy & Profit & Average \% \\
\hline Anchor & $1 / 1.34=\mathbf{0 . 7 4}$ & $5 / 6.33=\mathbf{0 . 7 9}$ & $7 / 10=\mathbf{0 . 7 0}$ & $\mathbf{0 . 7 4}$ \\
Occupancy & $0.2 / 1.34=\mathbf{0 . 1 5}$ & $1 / 6.33=\mathbf{0 . 1 6}$ & $3 / 10=\mathbf{0 . 3 0}$ & $\mathbf{0 . 2 0}$ \\
Profit & $0.14 / 1.34=\mathbf{0 . 1 0}$ & $0.33 / 6.33=\mathbf{0 . 0 5}$ & $1 / 10=\mathbf{0 . 1 0}$ & $\mathbf{0 . 0 8}$ \\
\hline & & & & $\mathbf{1 . 0 2}$
\end{tabular}

Based on AHP process table 3 shows the average percentages for the priorities. It shows that anchor was the most important one with the weight of $74 \%$,followed by occupancy with $20 \%$ weight and finally the profit by $8 \%$ weight. The result of AHP process is used as an input to goal programming.

The Goal Programming (GP) approach is one of the many models which have been developed to deal with the multiple objectives decision-making problems. A major advantage of goal programming over other techniques in dealing with real world decision problem is that it reflects the way managers actually make decisions. This model allows taking into account, simultaneously, many objectives while the decision-maker is seeking the best solution from among a set of feasible solutions. Therefore, after the priorities are set, the Goal Programming approach is applied to find the combination of tenant rental which would as a primary objective satisfy the anchor then Occupancy and finally to maximize profit. Since GP is an extension of Linear Programming, then GP must be formulated under the same limitations and assumptions.

In the goal-programming model, the decision variable is $\mathrm{Ti}$ which can take on any real values. The objective function, given below, seeks to minimize deviation from desired targets for limited resources.

$$
\text { Min } \mathrm{Z}=\mathrm{P}_{a}\left(\mathrm{~d} a^{-}, \mathrm{d}^{+}\right)+\mathrm{P}_{o}\left(\mathrm{~d} o^{-}, \mathrm{d} o^{+}\right)+\mathrm{P}_{m}\left(\mathrm{~d} m^{-}, \mathrm{d} m^{+}\right)
$$

Where " $a$ " denotes Anchor, " $o$ " denotes Occupancy desired, and " $m$ " denotes maximizing the profit. The "P" represents the priority and the " $d$ " represents the deviational variable. Therefore, $\mathrm{d}^{+}$represents overutilization and $\mathrm{d}^{-}$represents underutilization of a resource. The goal constraints represent the availability of limited resources. The right-hand side of each constraint reflects the targeted or desired level of the resource utilization. The system constraints in general are developed as follows:

$$
\sum_{i=1}^{11} \sum_{i=1}^{p} a_{t i} T_{t}+d_{k}^{-}-d_{k}^{+}-K_{i}
$$

Where, 
$a_{t i}=$ coefficient of tenant $\mathrm{t}$ in constraint $\mathrm{i}$

$T_{t}=$ tenant $\mathrm{t}$

$d_{k}^{-}=$deviational variable measuring under achievement

$d_{k}^{+}=$deviational variable measuring over achievement

$F_{i}=$ constraints "i" limitation

Where $d_{k}^{+}$is the positive deviation variable from overachieving the $\mathrm{i}^{\text {th }}$ constraint, $d_{k}^{-}$is the negative deviation variable from underachieving the $\mathrm{i}^{\text {th }}$ constraint, $T_{t}$ is the decision variables, and $a_{t k}$ is the decision variable coefficients. It is pertinent to note that $d_{k}^{+}, a_{k}^{-}$are called deviational variables because they represent the deviations above and below the right hand side of the constraint $i$. The deviational variable cannot be basic variables simultaneously, because by definition they are dependent. This implies that in any simplex iteration, at most, one of them can assume a positive value. Therefore, the objective function and constraints in this study are developed as follows. In this objective function the coefficents of $0.74,0.20$ and 0.08 are the weights from AHP approach for anchor, occupancy and maximizing profit respectively.

$$
\operatorname{MinZ}=0.74 \mathrm{~d}_{1}^{+}+0.20\left(\mathrm{~d}_{2}^{+}+\mathrm{d}_{3}{ }^{+}+\mathrm{d}_{4}{ }^{+}+\mathrm{d}_{5}{ }^{+}+\mathrm{d}_{6}{ }^{+}+\mathrm{d}_{7}{ }^{+}+\mathrm{d}_{8}{ }^{+}+\mathrm{d}_{9}{ }^{+}+\mathrm{d}_{10}{ }^{+}\right)+0.08 \mathrm{~d}_{11}{ }^{-}
$$

\section{Subject to:}

$$
\begin{aligned}
T_{7}+T_{8^{-}} d_{1}^{+}+d_{1}^{-} & =1 \\
1500 T_{1}+1800 T_{2}+2100 T_{3}+2400 T_{4}+3000 T_{5}+3600 T_{6}+6000 T_{7}+9000 T_{8}-d_{2}^{+}+d_{2}{ }^{-}= & =6 \\
T_{1}-d_{3}^{+}+d_{3}^{-} & =600 \\
T_{2}-d_{4}^{+}+d_{4}^{-} & =6 \\
T_{3}-d_{5}^{+}+d_{5}^{-} & =2 \\
T_{4}-d_{6}^{+}+d_{6}^{-} & =4 \\
T_{5}-d_{7}^{+}+d_{7}^{-} & =2 \\
T_{6}-d_{8}^{+}+d_{8}^{-} & =2 \\
T_{7}-d_{9}^{+}+d_{9}^{-} & =1 \\
T_{8}^{-} d_{10}^{+}+d_{10}^{-} & =1 \\
2250 T_{1}+2550 T_{2}+2800 T_{3}+3000 T_{4}+3500 T_{5}+3900 T_{6} & +6000 T_{7}+7500 T_{8}-d_{11}^{+}+d_{11}{ }^{-}=
\end{aligned}
$$

Where all $T_{t}$ and $d_{k}^{-}$and $d_{k}^{+} \geq 0$ 


\section{Mll Macrothink}

Table 4 provides the input data for the analysis of assignment of tenants in to the center with Goal Programming approach.

Table 4. The Goal Programming Formulation

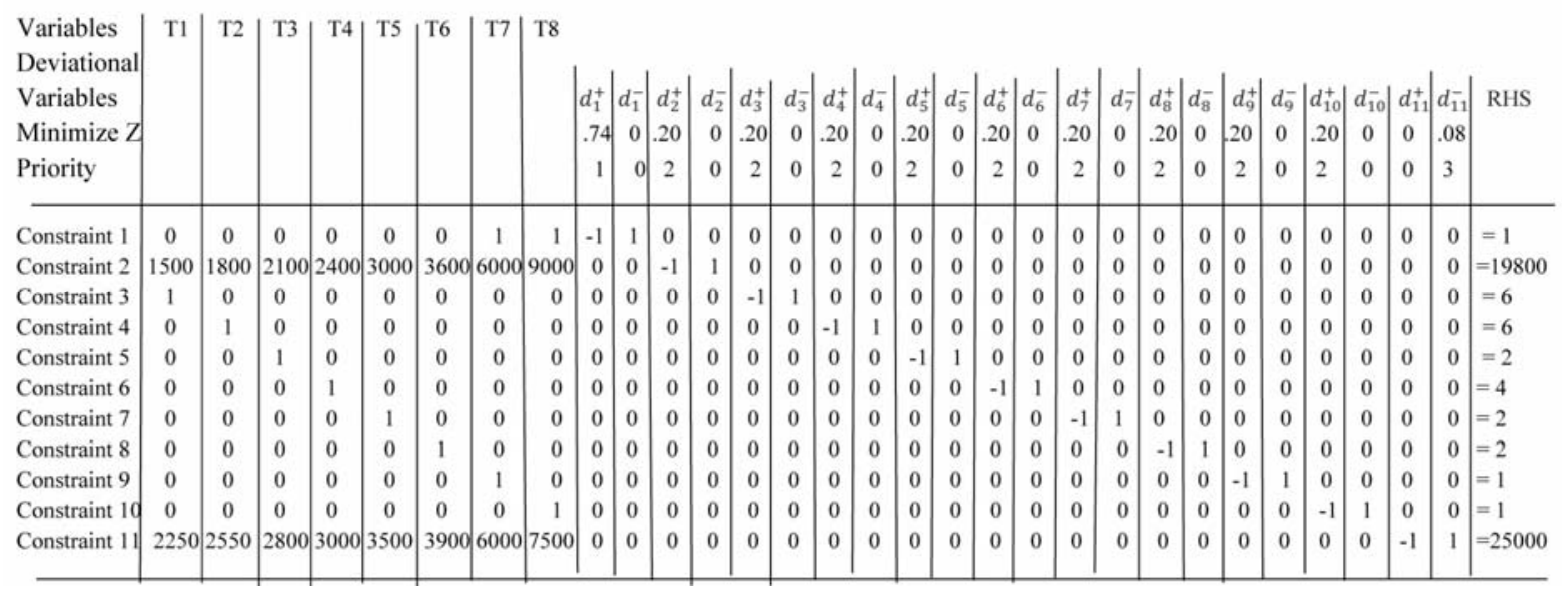

A goal programming program is used to solve this problem. The solution is provided in the following table.

\begin{tabular}{l|ccc} 
Variable & $\begin{array}{c}\text { Number of } \\
\text { Units }\end{array}$ & Unit Size & $\begin{array}{c}\text { Monthly } \\
\text { Rent }\end{array}$ \\
\hline T1 & 6 & 1500 & $\$ 2250$ \\
T2 & 1.56 & 1800 & 2550 \\
T3 & 0 & 0 & 0 \\
T4 & 0 & 0 & 0 \\
T5 & 0.67 & 3000 & 3500 \\
T6 & 0 & 0 & 0 \\
T7 & 1 & 6000 & 6000 \\
T8 & 0 & 0 & 0 \\
\hline Total & & 19800 & $\$ 25800$
\end{tabular}

With this solution all of the priorities have been achieved. However, in this situation the result can make senseonly if the variables assume discrete values. It is not possible to rent out 1.56 units of T2 or 0.67 units of T5. This is one of the deficiencies of Goal Programming approach to a multi objective decision making problem. Hence, in literature, it is recommended (Moore et al. 1993) to simply round off the values of the decision variables in the solution to nearest integer. After rounding, the following table is obtained. 


\section{Macrothink}

Table 6. Result of AHP and Goal Programming Combined After Rounding the Values

\begin{tabular}{llll} 
Variable & $\begin{array}{l}\text { Number of } \\
\text { Units }\end{array}$ & Unit Size & $\begin{array}{l}\text { Monthly } \\
\text { Rent }\end{array}$ \\
\hline T1 & 6 & 1500 & $\$ 2250$ \\
T2 & 1 & 1800 & 2550 \\
T3 & 0 & 0 & 0 \\
T4 & 0 & 0 & 0 \\
T5 & 1 & 3000 & 3500 \\
T6 & 0 & 0 & 0 \\
T7 & 1 & 6000 & 6000 \\
T8 & 0 & 0 & 0 \\
\hline Total & & 19800 & $\$ 25550$
\end{tabular}

The result of this table reveals that the first priority which was to have an Anchor to attract tenants to the center is achieved at $\mathrm{T} 7=1$, the second priority which was to be able to lease all the units and not have a fraction left out and utilize the 19,800 square feet is achieved. Meanwhile the maximum profit with integer values of $\$ 25,500$ is achieved. This profit is only $\$ 250$ off from the original solution when it was not rounded to nearest integer.

\section{Conclusion}

This is an empirical study examining the problem of facility assignment with conflicting goals. The goals were prioritized and the Analytical Hierarchy Process (AHP) was used to set the priorities. The input from the priority was given by the landlord. The result of AHP priorities was used as an input to the goal programming problem. Goal programming is an extension of Linear Programming which is a mathematical tool to handle multiple conflicting objectives. After priorities were set, the goal programming approach is applied to achieve the goals. The results demonstrated that all the goals formulated were met, however, the values of variables were not all integers. After rounding to nearest integer, the goals were achieved. An anchor is achieved to attract the tenants, all the facility is used at maximum capacity and maximum profit is achieved.

\section{References}

AbdelkrimYahia-Berrouiguet, \& Khadija Tissourassi. (2015). Application of goal programming model for allocating time and cost in project management: A case study from the company of costruction SEROR. Yugoslav Journal of Operations Research, 25(2), 283-289. https://doi.org/10.2298/YJOR131010010Y

Badri Masoud. (2001). A Combined AHP-GP Model for Quality Control System. International journal of production Economics, 2, 27-40.

Badri Mosoud. (1999). Combining the analytic hierarchy process and goal programming for global facility location-allocation problem. International Journal of Production Economics, 
2(3), 237-248.

Baumol, W., Wolfe, P. (1958). A warehouse location problem, Operations Research, 6(2), 252-263. https://doi.org/10.1287/opre.6.2.252

Erlenkotter, D. (1975). Capacity planning for large multilocation system: Approximate and incomplete dynamic programming approaches. Management Science, 22(3), 274-285. https://doi.org/10.1287/mnsc.22.3.274

Ekeezie Dan Dan, \& Onuoha Desmond (2013). Goal Programming:- An Application to Budgetary Allocation of An Institution of Higher Learning. Research journal in Engineering and Applied Sciences, 2(2).

Fabiane, D. O, Neida, M.P, \& Carlos, R.S (2003). Goal programming in a planning problem. Applied Mathematics and Computation, 14, 165-178.

Geoffrion, A. (1978). A guide to computer assisted methods for distribution system planning. Sloan Management Review, 24(5), 535-544.

Gyu, C. K., \& John, E. (2000). An application of zero-one goal programming in project selection and resource planning - a case study from the Woodward Governor Company. $\begin{array}{llll}\text { Computers } \& \quad \text { Operations } \quad \text { Research, } & 27,\end{array}$ https://doi.org/10.1016/S0305-0548(99)00080-5

Jucker, J., \& Carlson R (1976).The simple plant-location under uncertainty, Operations Research, 24(6), 1045-1055. https://doi.org/10.1287/opre.24.6.1045

Kennington, J., \& Unger, E. (1976). A new branch and bound algorithm for the fixed-charge transportation Problem. Management Science, 22(10), 1116-1126. https://doi.org/10.1287/mnsc.22.10.1116

Liang, T-F (2009)., Fuzzy multi-objective project management decisions using two-phase fuzzy goal programming approach. Computers \& Industrial Engineering, 57, 1407-1416. https://doi.org/10.1016/j.cie.2009.07.010

Lee, S. (1972). Goal Programming for Decision Analysis, Auerbach, Philadelphia.

Mairs, T,.Wakefield, G., Jonnson, E., \& Spielberg, K. (1978).On a production allocation and distribution Problem. Management Science, 24, 261-273. https://doi.org/10.1287/mnsc.24.15.1622

Masood.B, Donald,.D., \& Donna.D (2001). A comprehensive 0-1 goal programming model for project selection. International Journal of Project Management, 19, 243-252. https://doi.org/10.1016/S0263-7863(99)00078-2

Meyer, C. (1973). A long-run selection and timing analysis system for facility location: Plementation. Management Science, 20, 261-273. https://doi.org/10.1287/mnsc.20.3.261

Moore L., Lee Sang, \& Taylor Bernard. (1993). Management Science, $4^{\text {th }}$ edition. Allyn and Bacon publisher. 


\section{Macrothink}

Journal of Management Research

ISSN 1941-899X 2017, Vol. 9, No. 3

Mubiru. P. K. (2010). A goal programming model for allocating time and cost in project management. Proceedings of the 6th ORSEA Conference - 14-15 October, Kampala. http://orsea.net/2010.htm

Parcom, P. (2007). Developing your decision making skills. New Delhi, India: Lotus Press, 2007.

Patel, N (1979). Locating rural social service centers in India. Management Science, 25, 22-30. https://doi.org/10.1287/mnsc.25.1.22

Saaty, L. T. (1980). The analytical hierarchy process. New York: McGraw Hill.

Toregas, C., Swain, R., Revelle, C., \& Bergman L. (1971). The location of emergency service facilities. Operations Research, 19, 1363-1373. https://doi.org/10.1287/opre.19.6.1363

Tuckman, H., \& Holmblad, L. (1975). A modified simulation of Cyert, Feigenbaum, and March's Duopoly model. Management Science, 18, 694-705. https://doi.org/10.1287/mnsc.18.11.694 